\section{HLA in relation to retinopathy, residual beta- cell function and age at onset in Type 1 (insulin- dependent) diabetic patients}

Sir,

The possible rôle of genetic factors in the pathogenesis of microangiopathy was recently reviewed in Diabetologia by Barbosa and Saner [1] who have pointed out that most studies on Type 1 diabetic patients tend to show an increased frequency of $H L A-B_{15}$ or $-D_{4}$ in association with severe or proliferative retinopathy. However, as discussed, by these authors [1] one Icelandic study [2] has suggested that HLA- $B_{15}$ positive patients might be less prone to develop retinopathy. This issue may be further elucidated by a recent report from Hoogwerf et al. [3] demonstrating a decline of C-peptide secretion in Type 1 diabetic patients with increased duration of the disease. In addition, the stimulated C-peptide response was found to be less marked in patients who were younger than 10 years old at the onset of diabetes. Furthermore, HLA-DR 4 positive subjects had higher mean C-peptide values than $-\mathrm{DR}_{4}$ negative patients, irrespective of duration of the disease. The authors concluded that $\mathrm{DR}_{4}$ positive patients might be blessed by a better preservation of beta-cell function and discussed that this might favour improved glycaemic control, and hence delay or postpone microvascular complications in the diabetic patient [4]. A previous study of the Icelandic Type 1 diabetic population [5] has demonstrated that a subgroup of patients without retinopathy after a diabetes duration of 20 years or more required significantly less insulin than those with retinopathy after a comparable duration of the disease. The mean $( \pm S D)$ age at diagnosis of diabetes in the retinopathy-free subjects was $30 \pm 4$ years and $70 \%$ were females. Late onset of diabetes and female preponderance are believed to characterize "autoimmune" diabetes [6]. In a study of Type 1 diabetic patients with thyroid disorders in Iceland [7] the age at the onset of diabetes was $38 \pm 12$ years and $80 \%$ were females. They tended to require less than average insulin doses, eye and kidney complications were relatively rare and a higher frequency was found for HLA-B $\mathrm{B}_{15}$ than $-\mathrm{B}_{8}$ (relative risks 4.2 and 2.3 respectively).

Whether HLA-types are directly related to the age at onset of diabetes is presently controversial. HLA-DR ${ }_{4}$ has been reported to be significantly increased in Type 1 diabetes with age of onset after 40 years [8]. Other authors were unable to find such an association in analysing different subgroups according to their age at onset up to the age at onset of 25 years [9]. Likewise, the frequency of HLA- $B_{15}$ is similar in patients diagnosed 0-19 years old compared to those with an age at onset of above 30 years in the Icelandic diabetic patients (unpublished).

In conclusion, HLA-DR ${ }_{4}$ and probably HLA-B ${ }_{15}$, because of the strong linkage disequilibrium between these two, appear to be related to better preservation of residual beta-cell function. This is demonstrated by a greater C-peptide response in $H L A-D_{4}$ positive Type 1 diabetes patients. This may result in better glycaemic control in these patients and retard the development of long-term microvascular complications. These data may thus be compatible with the previous find- ing of less retinopathy in HLA- $B_{15}$ positive Type 1 diabetic patients in Iceland.

Yours sincerely,

R. Danielsen

\section{References}

1. Barbosa J, Saner B (1984) Do genetic factors play a rôle in the pathogenesis of diabetic microangiopathy? Diabetologia 27: 487-492

2. Danielsen R, Helgason T, Arnason A, Jónasson F (1982) HLA and retinopathy in Type 1 (insulin-dependent) diabetic patients in Iceland. Diabetologia 22: 297-298 (letter)

3. Hoogwerf BJ, Rich SS, Barbosa J (1985) Meal stimulated C-peptide and insulin antibodies in Type 1 diabetic subjects and their nondiabetic sublings characterized by HLA-DR antigens. Diabetes 34 : $440-445$

4. Tchobroutsky $G$ (1978) Relation of diabetic control to development of microvascular complications (Review) Diabetologia 15: 143-152

5. Danielsen R, Helgason T, Jónasson F (1983) Prognostic factors and retinopathy in type 1 diabetics in Iceland. Acta Med Scand 213: 323-326

6. Bottazzo GF, Cudworth AG, Moul DJ, Doniach D, Festenstein H (1978) Evidence for a primary autoimmune type of diabetes mellitus. Br Med J 2: 1253-1255

7. Danielsen R (1982) Thyroid disorders in type 1 (insulin-dependent) diabetics in Iceland. Icel Med J (Suppl) 15: 27 (Abstract)

8. Pittman WB, Acton RT, Barger BO, Bell DS, Go RCP, Murphy CC, Roseman JM (1982) HLA-A, -B, and -DR associations in type 1 diabetes mellitus with onset after age forty. Diabetes 31:122-125

9. Wolfe E, Spencer KM, Cudworth AG (1983) The genetic susceptibility to Type 1 (insulin-dependent) diabetes: Analysis of the HLADR association. Diabetologia 24: 224-230

Dr. R. Danielsen

Department of Clinical Physiology

Haukeland Hospital, University of Bergen

Bergen, Norway

\section{Incidence of diabetes in Scottish children}

Dear Sir,

The record linage method used by Patterson et al. [1], and in their recent update [2], involves several assumptions, i.e. (1) that all new cases are admitted to hospital; (2) that recording of admissions is complete, and coding correct; (3) that all patients from outwith Scotland can be identified as such; (4) that all Scottish cases have onsets in Scotland (otherwise the first admission in Scotland will appear to be 
the incident admission); (5) that admission intervals of more than 8 years are rare enough to be ignored; (6) that the correction factor, i.e. the proportion admitted in any year who have been admitted in previous years, is constant; (7) that revisions in the International Classification of Diseases (I. C. D.) codes have no effect on the method.

The same method has been applied to hospital discharge data for Tayside (population 382, 707) for the years 1980-83, using details of all admissions mentioning code 250 , diabetes mellitus, whether as primary or secondary diagnosis, in the years 1972-1983, for children under the age of 19 . A validation exercise was done by referral to case notes, and to a population-based register of insulin-using diabetic patients. (The register is based on hospital contacts, on school health records and on a survey of insulin prescriptions, and includes year of onset). The findings concerning each assumption were as follows: (1) the assumption is correct. The only patient started on insulin as an outpatient was a teenager who had been on an oral hypoglycaemic agent for 2 years, and who was not classified as insulin-dependent; (2) recording was not quite complete -3 out of 91 true incident cases had their first admission unrecorded, at least under code 250, and one "false incident" 1980 case had a 1975 admission unrecorded. These admissions were documented in case notes. The admission could have been coded under a vague code. Each patient misted was admitted in a later year. Only one case was incorrectly coded as diabetic; (3) some patients from outwith Tayside were recorded as being Tayside residents. Of 20 non-residents admitted, 16 were identified by nonTayside post-codes, but the other 4 were staying with relatives and coded as residents, although they normally lived outside Scotland; (4) 5 patients had their onset of diabetes outwith Tayside, and therefore appeared as "false incident" cases. Four had moved from other parts of Scotland; (5) long admission intervals were rare; two children had periods of 9 and 13 years between admissions, buth with clinic attendances in intervening years. Several others with long intervals were found to have left the area then returned, so could have had admissions in other areas; (6) the correction factor for readmissions did vary, being for Tayside 0.52 in $1980,0.28$ in $1981,0.43$ in 1982 and 0.44 in 1983. Hence applying a constant factor would have over-estimated the 1981 incidence, and applying the 1976 all-Scotland factor of 0.46 [1] would have over-estimated Tayside 1980-1983 incidence by $22 \%$; given data on sufficient previous years, there is no need to use a correction factor. The net effect then of the imperfections in the method would be to over-estimate Tayside incidence by an average of $2.5 \%$ a year, due to the inclusion of visitors and migrants (but not the 2 children with long admission intervals since both lived just outwith Tay- side). However, an all-Scotland survey would overcome the problem of internal migration, and would produce an over-estimate of only $1.5-2.0 \%$ per year, depending on how many previous years data were searched, and assuming Tayside data is representative. This is small compared to the mean annual increase in incidence of $8 \%$ found by Patterson et al. [1]. Hence even if tourism and migration were increasing over that period, such that there was no over-estimate in 1968 but a cumulative $12-16 \%$ by 1976 , only a small part of the rise in incidence would be explained; (7) the only change in I.C. D coding which was thought to be of possible importance was the dropping in the 9th Revision of specific mention of hypoglycaemia under code 250 . It seemed possible that the readmission figures could be spuriously lowered if more diabetic hypoglycaemia admissions were coded under 251 ("other disorders of pancreatic internal secretion"), which has a sub-code for unspecified hypoglycaemia, after the change to the 9th Revision. This would only matter if diabetic patients were listed under 251 without mention of 250 . In practice this happened on average only once a year in 1980-82; I.C. D 9 was introduced here in 1980.

I conclude that the method used by Patterson et al. [1, 2] gives a reliable indication of trends in the incidence of diabetes in children in Scotland, but that it is less accurate for smaller areas.

Yours sincerely,

N.R. Waugh

\section{References}

1. Patterson CC, Thorogood M, Smith PG, Heasman MA, Clarke JA, Mann JI (1983) Epidemiology of Type 1 (Insulin-dependent) diabetes in Scotland 1968-1976: evidence of an increasing incidence. Diabetologia $24: 238-243$

2. Grisso JA, Patterson CC, Smith PG, Thorogood M, Heasman MA, Webb J (1985) Continuing high incidence of diabetes mellitus in Scottish children. Diabetologia 28: 182-183 (Letter)

Dr. N.R. Waugh

Department of Community Medicine

Tayside Health Board

Dundee

Scotland

\section{Erratum}

Diabetologia, Volume 28, Number 5, May 1985, pp 282-285

T.M.Hollis, S. A. Strickberger: Inhibition of aortic histamine synthesis by $\alpha$-hydrazinohistidine inhibits increased aortic albumin accumulation in experimental diabetes in the rat.

Please note that the received date for this paper was 30 August 1984, and in revised form 11 February 1985. 